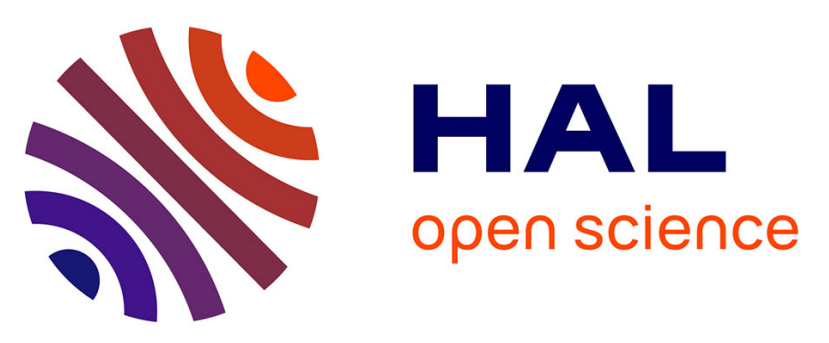

\title{
Cerebral microcirculation shear stress levels determine Neisseria meningitidis attachment sites along the blood-brain barrier
}

Emilie Mairey, Auguste Genovesio, Emmanuel Donnadieu, Christine Bernard, Francis Jaubert, Elisabeth Pinard, Jacques Seylaz, Jean-Christophe

Olivo-Marin, Xavier Nassif, Guillaume Dumenil

\section{To cite this version:}

Emilie Mairey, Auguste Genovesio, Emmanuel Donnadieu, Christine Bernard, Francis Jaubert, et al. Cerebral microcirculation shear stress levels determine Neisseria meningitidis attachment sites along the blood-brain barrier. Journal of Experimental Medicine, 2006, 203 (8), pp.1939-1950. 10.1084/jem.20060482 . hal-02425940

\author{
HAL Id: hal-02425940 \\ https://hal.science/hal-02425940
}

Submitted on 1 Jul 2020

HAL is a multi-disciplinary open access archive for the deposit and dissemination of scientific research documents, whether they are published or not. The documents may come from teaching and research institutions in France or abroad, or from public or private research centers.
L'archive ouverte pluridisciplinaire HAL, est destinée au dépôt et à la diffusion de documents scientifiques de niveau recherche, publiés ou non, émanant des établissements d'enseignement et de recherche français ou étrangers, des laboratoires publics ou privés. 


\title{
Cerebral microcirculation shear stress levels determine Neisseria meningitidis attachment sites along the blood-brain barrier
}

\author{
Emilie Mairey, ${ }^{1,3}$ Auguste Genovesio, ${ }^{4,5}$ Emmanuel Donnadieu, ${ }^{6,7}$ \\ Christine Bernard, ${ }^{1,3}$ Francis Jaubert, ${ }^{2}$ Elisabeth Pinard, ${ }^{8,9}$ Jacques Seylaz, ${ }^{8,9}$ \\ Jean-Christophe Olivo-Marin, ${ }^{4,5}$ Xavier Nassif,, ${ }^{1,2,3}$ \\ and Guillaume Duménil ${ }^{1,3}$
}

\author{
'Institut National de la Santé et de la Recherche Médicale (INSERM), U570 and 2AP-HP, Hôpital Necker-Enfants Malades, Paris, \\ F-75015 France \\ 3Université Paris Descartes, Faculté de Médecine René Descartes, UMR-S570, Paris, F-75006 France \\ ${ }^{4}$ Centre National de la Recherche Scientifique, URA2582 and ${ }^{5}$ nstitut Pasteur, Quantitative Image Analysis Unit, Paris, \\ F-75724 France \\ 6INSERM, U567 and 7 Institut Cochin, Département de biologie cellulaire, Paris, F-75014 France

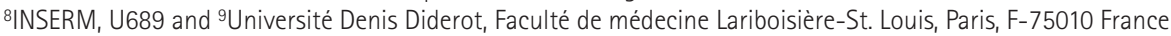

Neisseria meningitidis is a commensal bacterium of the human nasopharynx. Occasionally, this bacterium reaches the bloodstream and causes meningitis after crossing the bloodbrain barrier by an unknown mechanism. An immunohistological study of a meningococcal sepsis case revealed that neisserial adhesion was restricted to capillaries located in low blood flow regions in the infected organs. This study led to the hypothesis that drag forces encountered by the meningococcus in the bloodstream determine its attachment site in vessels. We therefore investigated the ability of $N$. meningitidis to bind to endothelial cells in the presence of liquid flow mimicking the bloodstream with a laminar flow chamber. Strikingly, average blood flows reported for various organs strongly inhibited initial adhesion. As cerebral microcirculation is known to be highly heterogeneous, cerebral blood velocity was investigated at the level of individual vessels using intravital imaging of rat brain. In agreement with the histological study, shear stress levels compatible with meningococcal adhesion were only observed in capillaries, which exhibited transient reductions in flow. The flow chamber assay revealed that, after initial attachment, bacteria resisted high blood velocities and even multiplied, forming microcolonies resembling those observed in the septicemia case. These results argue that the combined mechanical properties of neisserial adhesion and blood microcirculation target meningococci to transiently underperfused cerebral capillaries and thus determine disease development.

CORRESPONDENCE

Guillaume Duménil:

dumenil@necker.fr

Abbreviations used: BBB, blood-brain barrier; DIC, disseminated intravascular coagulation; FMS, fulminant meningococcal sepsis; HUVEC, human umbilical vein endothelial cell; Tfp, type IV pili.
Each bacterial pathogen triggers a distinct form of disease that reflects the properties of this bacterium in general and the set of virulence factors accumulated throughout evolution in particular. One key factor in determining disease development is the anatomical site targeted by the bacteria. Hence, our understanding of the mechanism of disease depends at least in part on finding out how and why a given pathogen targets a specific site. In the present study, we focused our efforts on understanding the patho-

The online version of this article contains supplemental material. A. Genovesio's present address is Institut Pasteur Korea, Seongbuk-gu, 136-791 Seoul, South Korea. genesis of the human pathogen N. meningitidis that has the capacity to colonize the brain after crossing the blood-brain barrier (BBB).

Neisseria meningitidis is a strictly human, Gramnegative, diplococcal pathogenic bacterium responsible for septicemia and meningitis (1). The human nasopharynx is the only known natural reservoir for $N$. meningitidis and transmission occurs directly via droplets. This bacterium colonizes the nasopharynx of a substantial proportion of the population, 3-30\% depending on the study $(2,3)$. Furthermore, these figures could underestimate the real carriage rate as the result of the method used in these screenings (4). 
Pathology is initiated when bacteria reach the bloodstream where they survive and proliferate. Several factors allowing survival in the blood have been described $(5,6)$, but the factors allowing access to the blood are largely unknown. In some patients, bacteria are cleared from the bloodstream and the only symptom is a short febrile flu-like episode (1). When the bacteremia is not rapidly cleared, two main and fairly distinct disease manifestations can develop: meningitis or septicemia during which bacteria may also cross the BBB. Fulminant meningococcal sepsis (FMS) is the most devastating form of sepsis with a mortality rate varying from 20 to $30 \%$ despite antimicrobial treatment and medical care $(1,7)$. FMS is characterized by a rapidly evolving septic shock and disseminated intravascular coagulation (DIC). Skin hemorrhages (purpura fulminans) are the hallmark of this form of disease. During the course of FMS, meningococci can cross the $\mathrm{BBB}(8)$ and invade the brain, where they proliferate uncontrolled as the main humoral and cellular host defense mechanisms are reduced (9). Alternatively, meningococcal meningitis can also develop in the absence of peripheral signs of sepsis. In this case, the inflammatory response remains localized to the brain and the bacteremia are often low or even undetectable. When treated, this form of meningitis has a relatively low rate of mortality and neurological sequelae compared with other types of bacterial meningitis.

Adhesion of N. meningitidis to human cells is a key step in the life cycle of this organism by allowing nasopharynx colonization. Bacterial adhesion is also thought to be a prerequisite for crossing the BBB (8). Evidence for such a hypothesis is provided by histological studies that reveal $N$. meningitidis tightly associated with endothelial cells in different organs including the choroid plexus (10). Neisserial type IV pili (Tfp) have long been recognized as playing an essential role in the pathogenesis of $N$. meningitidis and primary cultures of clinical isolates of pathogenic Neisseria are invariably piliated (11). The essential role of these filamentous structures in promoting adhesion of pathogenic Neisseria to mammalian cells has been well established in vitro and in vivo (12-14). Although the Tfp biogenesis machinery is complex as it is composed of some 15 distinct proteins (15), the main pilus component is the pilin encoded by the pilE gene (16). Meningococci also express several adhesins such as the Opa family of proteins, but the function of these proteins in encapsulated bacteria remains unclear (17).

Although the ability of $N$. meningitidis to colonize the human brain is a characteristic property of this pathogen, little is known about the causes for this tropism. This is at least in part the result of human-specific adhesive properties of $N$. meningitidis, which have hampered the development of animal models. Transgenic mice expressing human CD46 have been recently described as a model for meningococcemia (18), but this model fails to completely reproduce human disease as bacteria do not adhere to the transgenic mouse cells. To establish the basis for the tropism that this bacterium exhibits for the brain, we took advantage of a case of fulminant meningococcal sepsis by determining sites of bacte- rial attachment in the vasculature. Post-mortem examination showed that $N$. meningitidis adhesion to the blood vessel walls is not random and led to the hypothesis that the mechanical properties encountered in the bloodstream by the meningococci determine its attachment site and subsequent crossing of the BBB. An in vitro experimental approach using a laminar flow chamber assay combined with the in vivo observation of cerebral blood velocity using a closed cranial window strategy and quantitative image analysis allowed validation of this hypothesis.

\section{RESULTS}

\section{Neisseria meningitidis is found associated} with cerebral capillaries

Although N. meningitidis is frequently described as adherent to blood vessel walls during infection, the general pattern of
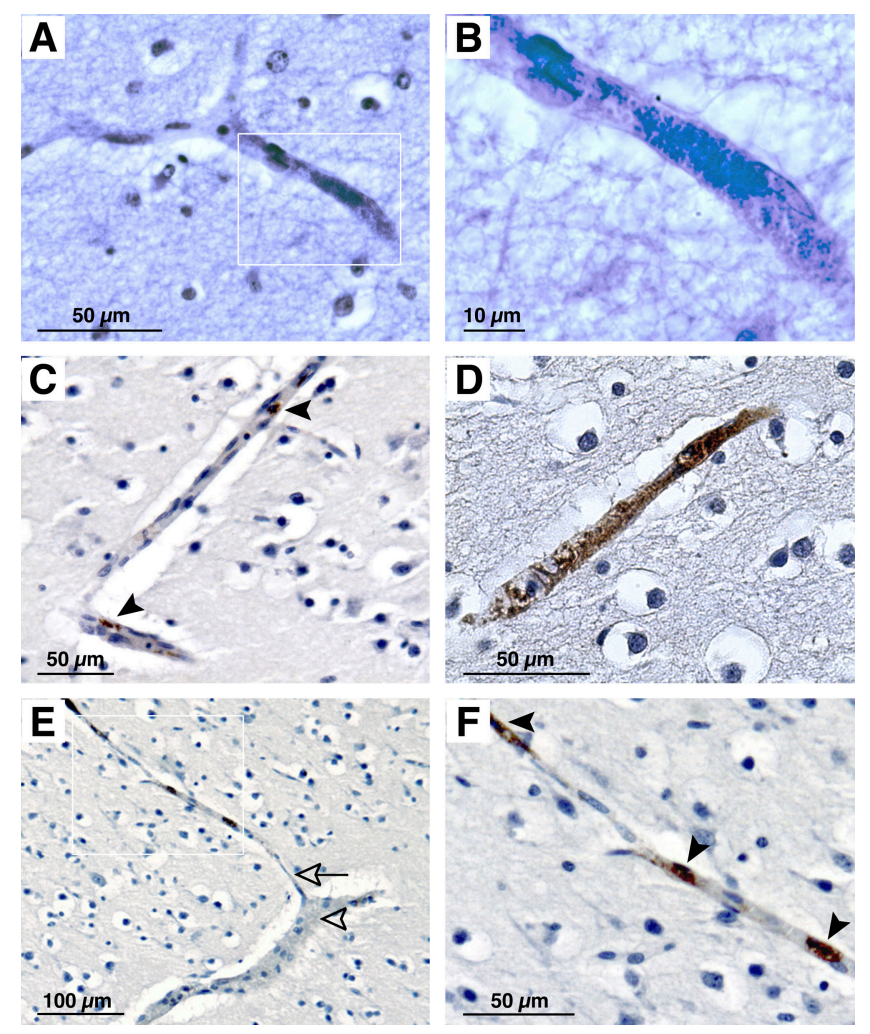

Figure 1. Histological analysis of a case of meningococcal septic shock showing bacterial colonies in cerebral capillaries. Paraffinembedded brain section samples were either analyzed by Gram-Weigert staining ( $A$ and $B$ ) or by immunohistochemistry with a polyclonal antibody directed against the strain cultured from the blood of this patient (C-F). (A) Brain section showing a bacterial microcolony inside a capillary. (B) Enlargement of the inset in A showing individual bacteria in the colony. (C) Two small colonies (arrowheads) visualized by immunohistochemistry. (D) Example of a large colony surrounded by edema. (E) Illustration of the favored localization of bacterial colonies in capillaries as opposed to arterioles. The arrowhead points to an arteriole and the arrow points to a connected capillary containing bacteria. (F) Enlargement of the inset in E. Arrowheads indicate immuno-labeled bacterial colonies present in the capillary. 
adhesion in the vasculature and the type of vessel involved remain poorly described. We took advantage of a previously reported case of fulminant meningococcal sepsis to address this question (10). This case is unusual in that death of the infant occurred before the arrival at the hospital and before any antibiotic treatment. Standard histology of paraffin-embedded brain samples revealed bacterial aggregates containing tens to hundreds of individuals tightly associated with blood vessel walls (Fig. 1, A and B). Immunohistochemistry confirmed that the aggregates were composed of $N$. meningitidis diplococci (Fig. 1, C-F). Some colonies were small, probably containing a few individual bacteria (Fig. $1 \mathrm{C}$, arrows), whereas others were large enough to obstruct the infected vessel (Fig. 1 D). Strikingly, bacterial aggregates were not associated with obvious signs of local inflammation such as the recruitment of polymorphonuclear cells. Edema, however, is frequently found around infected vessels (Fig. 1 D). Although it cannot be excluded that some proliferation occurred postmortem, several points argue that bacterial attachment and growth occurred before death as follows: (a) neisserial growth is sensitive to temperature; (b) observed bacterial growth respects tissue architecture by remaining inside blood vessels, something that would be unlikely in the case of post-mortem growth; and (c) the presence of edema surrounding infected vessels is indicative of a reaction of the tissue before death.

Bacteria were found in the brain as well as in the other organs, such as kidney and liver (unpublished data). In each case, they were found in peculiar vascular territories. In kidney, for example, bacterial colonies were mostly found in the medullar region rather than in the cortex region. In liver, bacteria were found in the portal spaces but not in lobules. In brain, bacteria were more abundant in the white matter than in the gray matter. Anatomical localization of a total of 117 meningoccocal colonies on brain slices revealed 93 colonies in the white matter as opposed to only 24 in the gray matter. Interestingly preferred sites of adhesion corresponded to regions of low cerebral blood blow as found in the white matter, where blood flow level is lower than in the gray matter $(19,20)$.

Strikingly, bacteria could not be detected in veins or arteries independently of size or location but were mainly located in capillaries (Fig. 1, E and F). The diameter of 35 cerebral vessels containing bacteria was determined on immunolabeled histological slides. The average vessel size harboring bacteria was $8.65 \pm 4.12 \mu \mathrm{m}$. Furthermore, infected vessels exhibited typical capillary morphology with a single endothelial cell layer resting on a basal lamina. In this patient, bacteria were therefore not randomly distributed in the circulation but preferentially formed compact microcolonies in capillaries located in low blood flow regions.

\section{Adhesion of Neisseria meningitidis to endothelial cells in the presence of flowing liquid}

Liquid flow such as the bloodstream generates drag forces on objects in the flow depending on their geometry and the viscosity of the blood and its velocity. These forces are generally expressed as a function of wall shear stress that represents the frictional force exerted by the blood on the vessel wall (21). In vivo, the pattern of shear stress is complex as it varies from 1 to 60 dynes $/ \mathrm{cm}^{2}$ depending in particular on vessel type and size (22). Specific adhesion of meningococci to capillaries in regions of low blood flow suggested that mechanical properties of the bloodstream are a central determinant in the pattern of adhesion of $N$. meningitidis during infection.

To test this hypothesis, we first set out to establish whether $N$. meningitidis adheres to endothelial cells in the presence of liquid flow. Experimentally, blood flow was modeled with a laminar flow chamber. Adhesion of a well-characterized piliated serogroup $\mathrm{C}$ strain $(6,23)$ was studied under defined
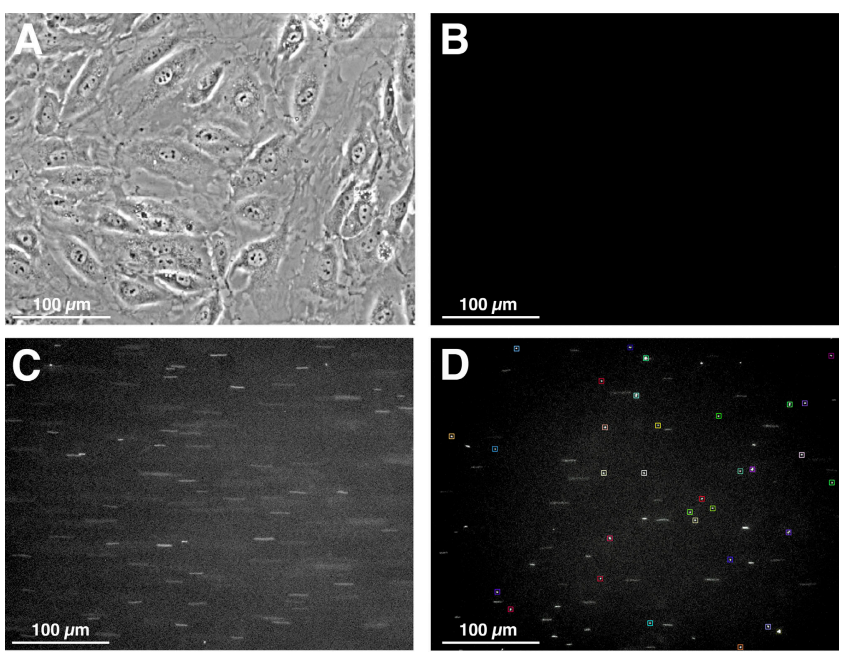

E

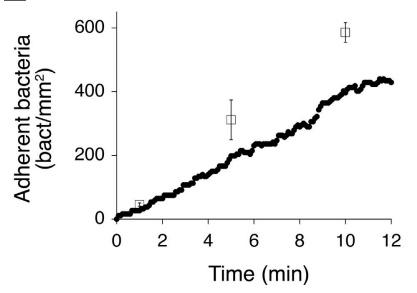

$F$

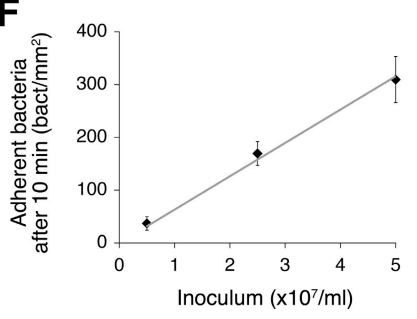

Figure 2. Analysis of $\mathbf{N}$. meningitidis adhesion on endothelial cells in the presence of liquid flow using in a laminar flow chamber.

(A) Endothelial cells forming a confluent monolayer on a glass slide are placed in the flow chamber and observed by phase contrast microscopy with a 20x lens. A typical sequence of three videoframes illustrates bacterial adhesion under various flow conditions: (B) before the introduction of bacteria into the chamber; (C) fluorescent bacteria flowing over the cells appear as short bright lines; and (D) bacteria adherent on the cell monolayer appear as still bright spots. Quantitative image analysis with the Quia software package allows automated identification of attached bacteria, which are then marked with colored squares. (E) Number of adherent bacteria determined as a function of time with the Quia software package shows bacteria accumulating with time in a linear fashion (circles). As a reference, results of a similar experiment performed in static conditions are also presented (squares). (F) The number of adherent bacteria plotted as a function of the concentration of bacteria introduced in the chamber shows a linear relationship between the inoculum and the number of adhering bacteria. 
shear stress conditions. Adherent human umbilical vein endothelial cells (HUVECs) were grown on glass slides and placed in a laminar flow chamber observed under an inverted microscope (see Materials and methods). Phase contrast observation showed the cell monolayer (Fig. 2 A) with $\sim 30$ cells per field $\left(0.14 \mathrm{~mm}^{2}\right)$. Bacteria expressing GFP were introduced in the chamber under a controlled flow.

Fluorescent bacteria passage over the cells was monitored by digital time-lapse video microscopy and analyzed by an image analysis software developed for this purpose. Spot detection was performed automatically by a multiresolution algorithm that identifies the bacteria on the basis of geometrical and intensity criteria computed after wavelet decomposition. This set-up allowed automatic measurement of bacterial attachment, detachment, and movement in real time. Bacteria were defined as adherent if they stayed stationary at least for five video frames. The number of adherent bacteria was either determined as a function of time or 10 frames $(\sim 300$ cells) were averaged after a given incubation time to gain statistical significance. Before introduction of the bacteria, little or no fluorescence was detected (Fig. 2 B). Relative to the values found in the bloodstream, a low shear stress value $(0.04$ dynes $/ \mathrm{cm}^{2}$ ) was arbitrarily chosen as a starting point. In the flow, bacteria appeared as bright lines when in movement (Fig. 2 C) and as spots in case of adhesion. When identified as stationary by the image analysis software, bacteria were labeled with colored squares (Fig. 2 D).

Analysis of time-lapse videos allowed several observations (Video 1, available at http://www.jem.org/cgi/content/full/ jem.20060482/DC1). Upon binding to cells, bacteria came to a sudden stop rather than slowing down progressively. Furthermore, after binding, little detachment occurred and bacteria remained attached to the cells throughout the assay. During the assay, bound bacteria exhibited a short-range movement $(<10 \mu \mathrm{m})$ that seemed to follow cellular movement. A key property of Tfp is to allow bacterial aggregation, so we expected interactions between flowing and adherent bacteria by pili-pili interactions, but this was rarely observed in these conditions.

From a quantitative point of view, adhesion rate under low flow was comparable to that observed in the standard static adhesion assay. With an initial inoculum of $7.5 \times 10^{7}$ bacteria $/ \mathrm{ml}$ and a shear stress level of 0.04 dynes $/ \mathrm{cm}^{2}$, bacteria adhered progressively to the endothelial monolayer at a constant rate of 38 bacteria per minute per $\mathrm{mm}^{2}\left(1 \mathrm{~mm}^{2}\right.$ corresponding to $\sim 200$ cells; Fig. 2 E, circles). As a comparison, the same experiment was performed with the standard adhesion assay in static conditions with adhesion efficiency determined by dilution plating of bound bacteria after repeated washes. With the same inoculum in static conditions, 59 bacteria adhered per minute and per $\mathrm{mm}^{2}$ of endothelial monolayer (Fig. $2 \mathrm{E}$, squares). In the presence of low shear stress level, adhesion is therefore as efficient as in static conditions. To further validate this experimental approach, we tested whether efficiency of adhesion in the presence of flow was linear with regard to inoculum. As expected, the amount of adherent bacteria after $10 \mathrm{~min}$ is proportional to the inoculum at least over the range of 5-50 million bacteria per $\mathrm{ml}$ (Fig. 2 F). Consistent with the human specificity of meningococcal adhesion, the rat brain RBE4 endothelial cells line (24) did not allow any bacterial binding in these conditions (unpublished data).

\section{Neisserial Tfp are necessary for adhesion under flow}

Next, we aimed to determine the molecular basis of the adhesion under liquid flow. As Tfp are key determinants of adhesion of encapsulated $N$. meningitidis, we therefore examined the role of pili in adhesion under shear conditions by analyzing piliation mutants. A nonpiliated pilE mutant was introduced into the flow chamber under the aforementioned conditions. The bacteria passed over the cells carried away with the flow, rarely binding to cells. After a period of $10 \mathrm{~min}$, the number of adherent bacteria present on 10 fields was averaged. For the nonpiliated strain, $10 \pm 6$ bacteria were bound per $\mathrm{mm}^{2}$ of monolayer (Fig. $3 \mathrm{~A}$, PilE). In the same conditions, $209 \pm 33$ wild-type bacteria were bound per $\mathrm{mm}^{2}$ (WT), demonstrating that pili are necessary to mediate efficient meningococcal adhesion in the presence of drag forces. Similar results were obtained with a pilC1 mutant, which harbors nonadhesive pili (PilC1). Tfp are highly dynamic structures with rapid retraction and elongation. To test whether pili-dynamic properties were important for adhesion under shear stress, we used the pilT mutant that fails to retract its pili $(25,26)$. The number of adherent pilT mutants was similar to that observed with the wild-type strain in the same conditions (PilT), indicating that the dynamic properties of pili are not necessary to mediate adhesion in the presence of liquid flow. Collectively, these data demonstrate that N. meningitidis adhesion under shear conditions is mediated by Tfp, but is independent of their retraction capacities.

\section{High shear stress levels inhibit neisserial Tfp-mediated adhesion}

We next evaluated the optimal shear stress for pili-dependent adhesion of $N$. meningitidis to endothelial cells by analyzing adhesion under different shear stress levels. With a $2 \times 10^{8}$ bacteria/ml inoculum in the presence of 0.04 dynes $/ \mathrm{cm}^{2}$ of shear stress, $701 \pm 228$ bacteria were bound per $\mathrm{mm}^{2}$ of monolayer after $10 \mathrm{~min}$ (Fig. $3 \mathrm{~B}$, squares). Increasing the flow to 0.22 dynes $/ \mathrm{cm}^{2}$ led to a sharp decrease in adhesion as only $150 \pm 57$ bacteria were bound per $\mathrm{mm}^{2}$ of monolayer. At higher shear stress values such as 0.7 dynes $/ \mathrm{cm}^{2}$, no binding was observed. Enhanced shear stress therefore leads to a sharp decrease in the binding ability of meningococci and hardly any binding can be observed $>0.5$ dynes $/ \mathrm{cm}^{2}$. Surprisingly, this result suggests that $N$. meningitidis is not able to bind to endothelial cells in the bloodstream where reported average shear stress levels are $>1 \mathrm{dyne} / \mathrm{cm}^{2}$. To strengthen this unexpected finding, the same experiment was performed using hCMEC/D3 cells, a recently described human brain endothelial cell line (27). With the same inoculum, adhesion to hCMEC/D3 cells was approximately twofold less efficient 

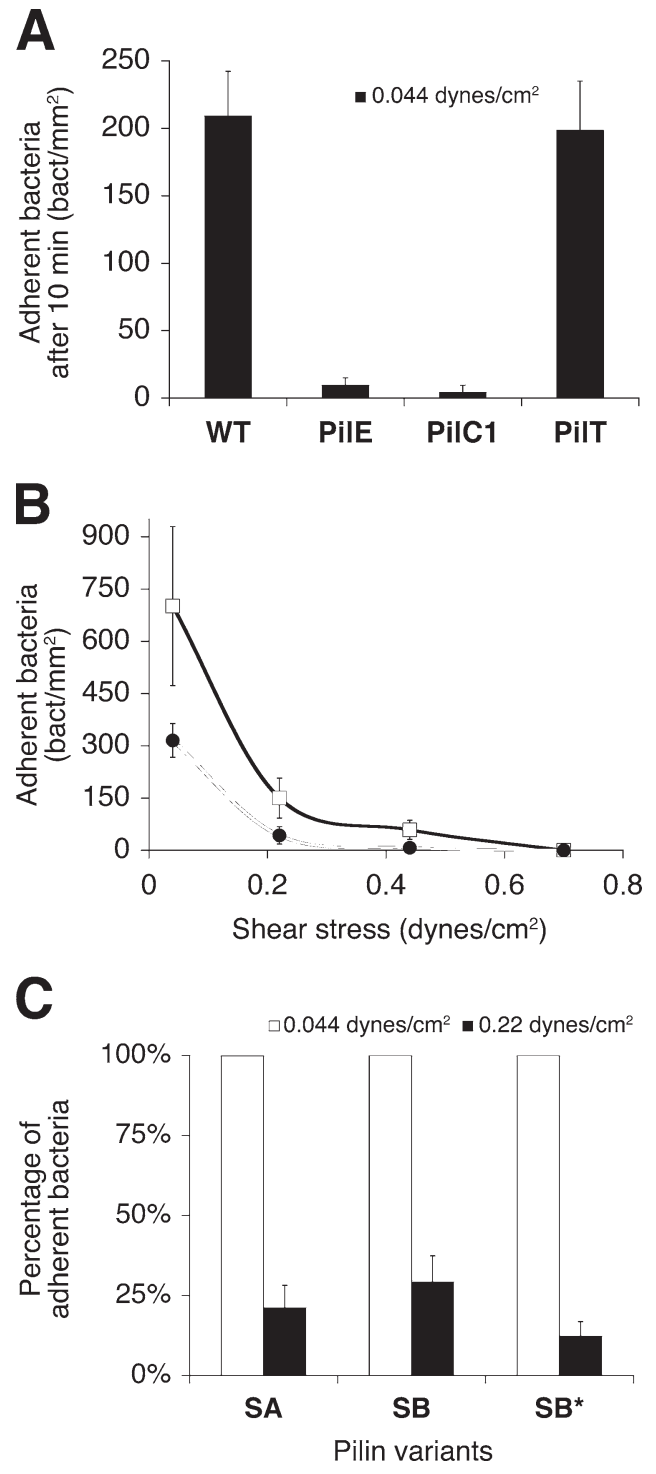

Figure 3. Determination of the molecular basis of $N$. meningitidis adhesion under liquid flow and the optimal flow for efficient adhesion. (A) Testing of different mutants deficient for pili biogenesis and function shows that Tfp are necessary for adhesion under flow. After introduction in the flow chamber containing the endothelial cells in the presence of $0.04 \mathrm{dynes} / \mathrm{cm}^{2}$, the number of bacteria per $\mathrm{mm}^{2}$ was determined. Compared with the wild-type strain (WT), the pilE-deficient mutant (PilE) does not express the Tfp major subunit, the pilC1-deficient strain (PilC1) expresses nonfunctional pili, and the pilT mutant (PilT) fails to retract its pili. (B) The ability of N. meningitidis to adhere to an endothelial cell monolayer at different flow velocities was determined to show that increased shear stress strongly inhibits adhesion. The concentration of the bacterial suspension introduced in the chamber is constant throughout each experiment and only the shear stress levels varied. The number of bacteria per $\mathrm{mm}^{2}$ is plotted as a function of shear stress level. Squares represent the results on HUVEC cells and circles on the brain-derived hCMEC/D3 endothelial cell line. (C) Comparison of adhesion behavior for three pilin variants at 0.04 (white bars) and 0.2 dynes $/ \mathrm{cm}^{2}$ (black bars) shows that adhesion is also inhibited by shear stress increase in these variants. Results are expressed as the percentage of the number of bacteria adhering at 0.04 dynes $/ \mathrm{cm}^{2}$.
(Fig. 3 B, circles). Nevertheless, increasing values of shear stress led to a sharp decrease in adhesion efficiency in brainderived endothelial cells, indicating that the observed adhesion pattern is a general property of endothelial cells.

The N. meningitidis pilin subunit undergoes frequent antigenic variations that modulate adhesion to host cells (23) and could potentially generate diversity in the adhesion behavior in the presence of liquid flow. This question was addressed by testing the adhesive properties of pilin variants in the flow chamber assay. The pilE gene of the strain used in this study expresses a pilin variant called SB pilin. The pilE locus of two other pilin antigenic variants, $\mathrm{SA}$ and $\mathrm{SB}^{*}$, have been sequenced and studied in this strain (23). SB and $\mathrm{SB}^{*}$ are considered as high-adhesive pilin, whereas SA is characterized by lower efficiency adhesion. To address whether pilin variants behave differently under shear conditions, we compared the adhesion capacity of $\mathrm{SA}, \mathrm{SB}$, and $\mathrm{SB}^{*}$ pilin variants under a range of shear stress. Results were plotted as the percentage of adhesion obtained at 0.04 dynes $/ \mathrm{cm}^{2}$. As shown in Fig. $3 \mathrm{C}$, the number of adherent bacteria of the three pilin variants decreased $\sim 75 \%$ when shear stress was increased from 0.04 to 0.2 dynes $/ \mathrm{cm}^{2}$, indicating that pilin antigenic variation does not provide any specific modulation of bacterial adhesion under shear conditions. Collectively, these results show that shear stress strongly inhibits neisserial adhesion.

\section{Cerebral capillary blood flow transiently provides conditions compatible with neisserial adhesion}

Shear stress values for vessels $<20 \mu \mathrm{m}$ in diameter have rarely been reported but average values for the mesenteric microcirculation have been estimated as $\sim 30$ dynes $/ \mathrm{cm}^{2}(28,29)$. In brain capillaries, blood flow is high but also very heterogeneous, suggesting that a wide range of shear stress levels can occur $(30,31)$. The question is whether this heterogeneity could provide low enough shear stress levels to allow $N$. meningitidis binding. Ideally, this question would be addressed by introducing bacteria in the circulation of an animal model in which $N$. meningitidis crosses the BBB after adhering to brain endothelial cells. Unfortunately, N. meningitidis adhesion is human specific and does not occur in the presence of animal cells, thus ruling out the possibility to perform this experiment. Nevertheless, animal models allow precise in vivo measurements of blood velocity, which can be correlated with adhesive properties of meningococci in the flow chamber assay.

Laser scanning fluorescence confocal microscopy through a closed cranial window was used to visualize the movement of fluorescently labeled erythrocytes in rats (Fig. 4 A and Video 2, available at http://www.jem.org/cgi/content/ full/jem.20060482/DC1). This approach allowed us to assess erythrocyte behavior at the level of individual capillaries. The QUIA software program was adapted to determine erythrocyte velocity along capillaries (Fig. $4 \mathrm{~B}$ and Video 3, available at http://www.jem.org/cgi/content/full/jem.20060482/DC1). We used red blood cells velocity as an approximation of blood velocity to calculate shear stress levels found in cerebral capillaries. 
Blood velocities found in two representative examples of capillaries are shown in Fig. 4 C. The velocity of four individual erythrocytes that passed through a $90-\mu \mathrm{m}-\mathrm{long}$ capillary portion was determined for both capillaries and plotted as a function of the erythrocyte position in the observed capillaries. Average blood velocity in these capillaries was $163 \pm 21 \mu \mathrm{m} / \mathrm{s}$ and $766 \pm 69 \mu \mathrm{m} / \mathrm{s}$ and corresponding shear stress levels estimated from these values were 5 and 23 dynes $/ \mathrm{cm}^{2}$, respectively (see Materials and methods). According to the results obtained with the laminar flow chamber, N. meningitidis could not bind to these vessels, at least not during the period of observation. Blood velocities observed in arterioles were always too high to be recorded with our video system, implying shear stress values incompatible with adhesion. Erythrocyte velocities in cerebral venules were remarkably regular with an average value of $377 \pm 198 \mu \mathrm{m} / \mathrm{s}$, which corresponds to $3 \pm 1.5$ dynes $/ \mathrm{cm}^{2}$ for a $40-\mu \mathrm{m}$-diameter venule and flow stop or inversion was never observed. According to our in vitro assay, this type of shear stress would efficiently preclude bacterial adhesion.

Interestingly, in some capillaries, red blood cells exhibit a slower velocity and sometimes even stop for various amounts of time before moving along, indicating transient slowing down of blood flow. One such example is described in Fig. $4 \mathrm{D}$ (see also Video 4, available at http://www.jem.org/cgi/ content/full/jem.20060482/DC1). To confirm that erythrocytes moving at slow velocities or even stopping reflect plasma flow, we introduced 1- $\mu \mathrm{m}$-diameter fluorescent beads in the circulation of the animals. Fluorescent beads the size of bacteria exhibited similar behavior as erythrocytes (unpublished data), indicating that erythrocyte velocities reflect conditions encountered by bacteria in the circulation. Among the 11 labeled erythrocytes observed passing through this capillary at the average velocity of $209 \pm 63 \mu \mathrm{m} / \mathrm{s}, 1$ of them slowed to low velocities in the middle of the observed capillary section and came to a stop (Fig. 4 D, red line). Another example of capillary exhibiting slow blood velocities is presented in Fig. 4 E. In this case, the overall blood flow was low $(63 \pm 24 \mu \mathrm{m} / \mathrm{s})$ and even stopped repeatedly (Fig. $4 \mathrm{E}$, blue line). Corresponding shear stress levels were calculated in the cases of low blood flow described in Fig. 4 (D and E, blue and red lines) and plotted as a function of time (Fig. 4 F). The dotted line indicates shear stress levels compatible with $N$. meningitidis adhesion $\left(<0.5\right.$ dynes $\left./ \mathrm{cm}^{2}\right)$. Shear stress remains $<0.5$ dynes $/ \mathrm{cm}^{2}$ for $1.5-2 \mathrm{~s}$ before increasing to $>3$ dynes $/ \mathrm{cm}^{2}$. These results show that, in certain capillaries, blood flow transiently decreases to values compatible with neisserial adhesion.

Analysis of 77 individual cerebral capillaries from five different animals revealed 9 capillaries exhibiting velocities compatible with $N$. meningitidis adhesion for at least one labeled erythrocyte during observation. Periods of time compatible with $N$. meningitidis adhesion were comprised between $0.1 \mathrm{~s}$ and $30 \mathrm{~s}$. Although only a subset of capillaries reduce their shear stress levels and only for short periods of time, this is likely compensated by the high number of capillaries found
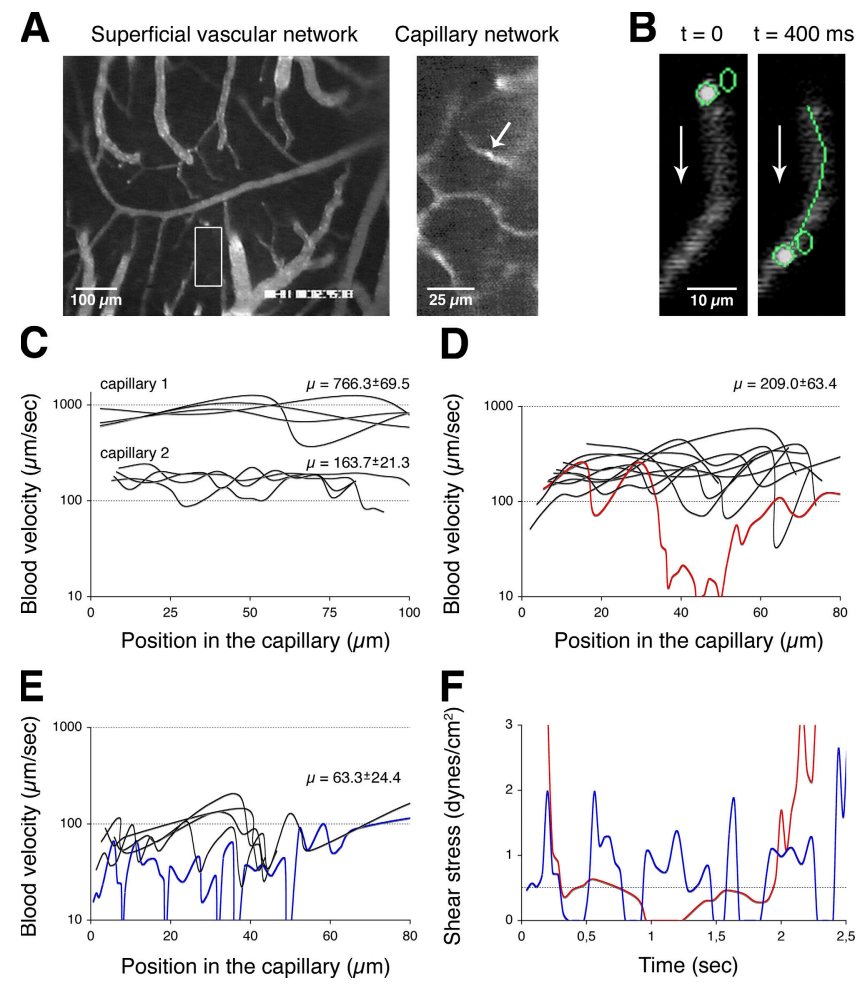

Figure 4. In vivo imaging of cerebral microcirculation in anesthetized rats equipped with a closed cranial window shows that local and transient blood flow reductions through cerebral capillaries provide conditions compatible with neisserial adhesion. A tracer dose of FITC-dextran was used to label the vascular network. Erythrocytes were labeled with FITC and injected into the animal. (A) Confocal microscope view through the cranial window of the superficial vascular network (10x lens) and a capillary network at a depth of $\sim 200 \mu \mathrm{m}$ below the pia mater (20x lens) in the region corresponding to the inset in the left panel. The arrow points to a passing erythrocyte. (B) Example of tracking of erythrocytes using the Quia image treatment software to determine blood velocity in capillaries. Panels show the object detection and tracking at two successive time points separated by $400 \mathrm{~ms}$. The arrow indicates flow direction. (C) Computed blood velocities in portions of two typical capillaries represented as a function of the position along the capillary ( $\mu$ corresponds to the average velocity). (D) Blood velocities in a portion of capillary with temporary reduction in flow velocity (red line). (E) Blood velocities in another capillary exhibiting average low flow $(63 \mu \mathrm{m} / \mathrm{s})$ with a temporary further reduction in flow velocity (blue line). (F) Further analysis of the two periods of time where blood flow is reduced as described in $D$ and $E$. Shear stress values were calculated from erythrocyte velocities and plotted as a function of time. The dotted line identifies shear stress levels compatible with neisserial adhesion $\left(<0.5\right.$ dynes $\left./ \mathrm{cm}^{2}\right)$.

in the brain. At any one given time, bacteria circulating through the brain microcirculation will thus encounter a significant number of capillaries exhibiting shear stress levels compatible with their adhesion.

\section{Pili-dependent adhesion of $N$. meningitidis is irreversible}

Although the aforementioned results indicate that N. meningitidis occasionally encounters conditions compatible with adhesion in the bloodstream, they also show that blood flow 
only transiently slows down before returning to higher values. In the example presented in Fig. $4 \mathrm{D}$, the flow increases to $\sim 100 \mu \mathrm{m} / \mathrm{s}$, which corresponds to 3 dynes $/ \mathrm{cm}^{2}$. To determine whether pili-dependent adhesion of $N$. meningitidis allows bacteria to resist enhanced fluid shear stress once initial adhesion has occurred, we submitted adherent bacteria to high flow in the laminar flow chamber. Piliated bacteria were allowed to bind to cells under slow flow (0.04 dynes/ $\mathrm{cm}^{2}$ ) for $10 \mathrm{~min}$. The monolayer was then washed at a shear stress of 0.04 dynes $/ \mathrm{cm}^{2}$ and the number of bound bacteria on the monolayer was determined. Shear stress was increased to values between 5 and 40 dynes $/ \mathrm{cm}^{2}$ during $5 \mathrm{~min}$ (Fig. 5 A). Bacterial concentration on the monolayer was determined and the results were plotted as the percentage of adhesion obtained at 0.04 dynes $/ \mathrm{cm}^{2}$. As shown in Fig. $5 \mathrm{~A}$, little detachment was observed for the wild-type strain even at high shear stress levels. At 5 dynes $/ \mathrm{cm}^{2}$, detachment was not significant and at 40 dynes $/ \mathrm{cm}^{2}, 57 \%$ of bound bacteria remained attached. Similar results were obtained with the brain-derived hCMEC/D3 cell line (unpublished data). We extended these experiments to other pilin variants. SA, $\mathrm{SB}$ and $\mathrm{SB}^{*}$ expressing variants were analyzed after the same procedure. As shown in Fig. $5 \mathrm{~B}$, SA and SB pilin variants did not detach from cells when they were submitted to a high shear. The slight decrease observed with $\mathrm{SB}^{*}$ was not statistically significant. Pilin antigenic variation therefore does not seem to play any specific role in adhesion maintenance under dynamic conditions. To address whether pili retraction was involved in this process, a pilT mutant was analyzed. When submitted to a high shear, the mutant remained attached to cells showing that pili retraction is not necessary for the adhesion maintenance (Fig. 5 B, PilT).

The aforementioned results show that $N$. meningitidis is able to remain attached to cells even if the environmental shear increases suddenly. We extended these results by determining whether the presence of high shear stress was compatible with the formation of bacterial colonies on the cellular surface as observed in vivo (Fig. 1). Bacterial growth up to 2 dynes $/ \mathrm{cm}^{2}$ during $>7 \mathrm{~h}$ was studied (Fig. $5 \mathrm{C}$ and Video 5, available at http://www.jem.org/cgi/content/ full/jem.20060482/DC1). Initially bound to cells as individuals (Fig. $5 \mathrm{C}, 0 \mathrm{~h}$ ), bacteria started to multiply on cells (Fig. $5 \mathrm{C}, 4 \mathrm{~h}$ ) and to form large aggregates in three dimensions (Fig. $5 \mathrm{C}, 7 \mathrm{~h} 30 \mathrm{~min}$ ). When the same experiment was performed in absence of flow, colonies of similar morphology and size formed with the same kinetics. This observation was quantified by measuring colony sizes in the presence and in the absence of flow but in otherwise identical conditions. After $4 \mathrm{~h}$ in the absence of flow, average colony size was $81.4 \pm 45.7 \mu^{2}$. After $4 \mathrm{~h}$ of growth in the presence of 0.88 dynes $/ \mathrm{cm}^{2}$ and 2.2 dynes $/ \mathrm{cm}^{2}$, average

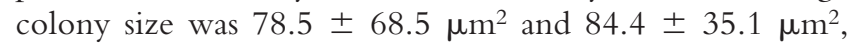
respectively. Shear stress therefore does not influence the growth of $N$. meningitidis on a cellular monolayer; bacteria can remain attached over long periods of time and dividing cells remain attached to the colony.
A

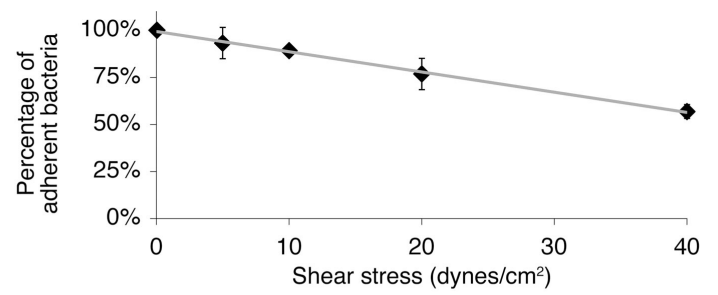

B
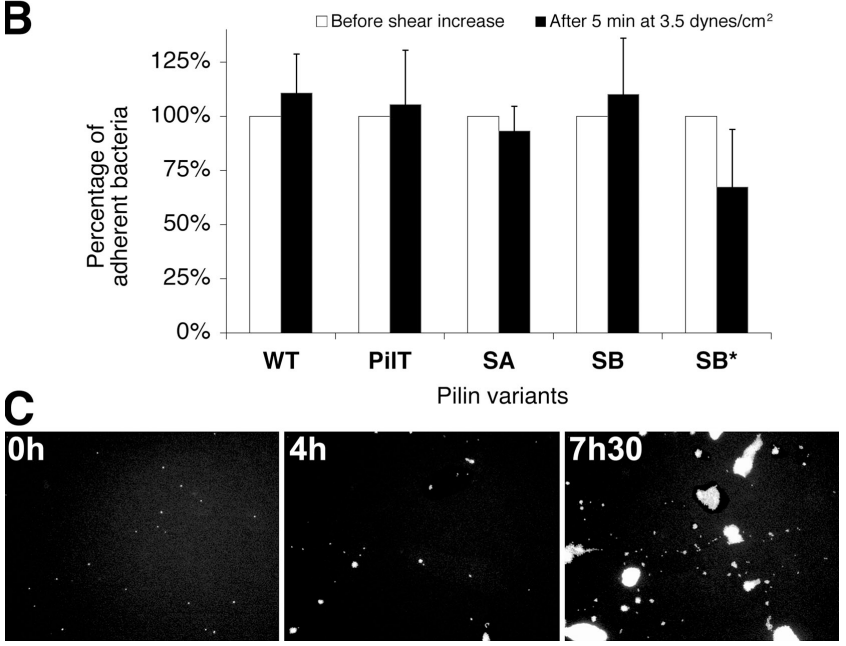

Figure 5. After initial adhesion, N. meningititidis is resistant to high liquid flow and proliferates in the presence of high shear stress. (A) The ability of the wild-type strain to resist to high shear stress levels was determined. The number of adherent bacteria was first determined after adhesion at 0.04 dynes $/ \mathrm{cm}^{2}$ and washing of unbound bacteria at the same shear stress level. Shear stress was then gradually increased in 5-min steps up to $40 \mathrm{dynes} / \mathrm{cm}^{2}$ and the number of bacteria that remained bound was determined. Results were plotted as a percentage of initial adhesion. (B) The ability of different strains to resist to high shear stress level was determined. After initial adhesion at 0.04 dynes $/ \mathrm{cm}^{2}$ (white bars) and shear stress increase at $3.5 \mathrm{dynes} / \mathrm{cm}^{2}$ during $5 \mathrm{~min}$, the number of bacteria that remained bound was determined (black bars). Results were plotted as a percentage of initial adhesion. Three different pilin variants $\left(S B, B^{*}\right.$, and $\left.S A\right)$ and a pilus retraction mutant (PilT) were compared with wild type (WT). (C) Videoframes illustrating growth of adherent bacteria on cells under shear conditions $\left(2\right.$ dynes $\left./ \mathrm{cm}^{2}\right)$. Bacteria were allowed to adhere at $0.04 \mathrm{dynes} / \mathrm{cm}^{2}$, unbound bacteria were removed, and flow was increased and maintained at 2 dynes $/ \mathrm{cm}^{2}$ for the indicated times. Compact bacterial colonies appear and increase in size, reminding those observed in the sepsis case (Fig. 1).

\section{DISCUSSION}

Key steps of neisserial pathogenesis remain largely hypothetical. This is at least in part the result of human-specific adhesive properties of $N$. meningitidis, which have hampered the development of animal models. Mice expressing human CD46 have been described as a model for meningococcemia (18), but the role of CD46 in meningococcal adhesion is under discussion $(32,33)$ making this model inappropriate for this study. As this bacterium binds to human endothelial cells, it is generally assumed that this adhesion property is linked to its ability to cross the BBB. However, the effect of the drag forces generated by the bloodstream on the ability of 
N. meningitidis to adhere to endothelial cells had never been studied. To address this question, an experimental system was developed to place bacteria in contact with endothelial cells in the presence of controlled liquid flow. One key element of the set up was the development of a dedicated software program to quantify the adhesion capacity of bacteria in different conditions. Unexpectedly, it was found that the rapid liquid flows present in the main bloodstream strongly inhibit N. meningitidis binding to endothelial cells. We have tested several cell cultures of different origin, either primary or immortalized cell lines (endothelial as well as epithelial) with the same end result. In particular, we have done the experiment with an immortalized cell line derived from human cerebral capillaries (hCMEC/D3), which recapitulates most of the characteristics of endothelial cells found in the capillaries that constitute the BBB (27). Inhibition of initial attachment by flow therefore probably applies to the different tissues encountered by meningoccoci including the BBB.

In contrast, selectin-dependent lymphocyte binding to endothelial cells is adapted to the presence of flow. Despite flow-generated drag forces, selectins are able to bind to their sugar ligands on endothelial cells, enabling free lymphocytes in the vascular flow to tether to endothelial cells and to roll along vessel walls in search for inflammation sites (34). A key feature of selectin-dependent adhesion is that it is enhanced by increased wall shear stress. Interestingly, in certain uropathogenic strains, the bacterial type I piliassociated fimbrial adhesin FimH demonstrates a similar behavior (35-37). It is noteworthy that FimH varies among uropathogenic Escherichia coli strains and most alleles do not exhibit enhanced adhesion in the presence of wall shear stress. For Neisseria spp., PilE, the main component of Tfp, undergoes frequent antigen variation by recombination events with silent gene cassettes and this process is known to affect pili-dependent adhesion $(23,38)$. Three of these pilin variants were tested, but none of them exhibited enhanced adhesion with wall shear stress. Nevertheless, the possibility remains that other strains or other variants present such adhesive properties.

It is important to note, however, that the evolutionary pressure exerted on $N$. meningitidis does not occur during the blood phase of the infection but rather in nasopharynx colonization (39). In terms of evolution, growth in blood is a dead-end for the bacteria, as untreated infection will lead to death of the host without any possibility of transmission. The adhesive properties could therefore rather be adapted to life in the human nasopharynx where flow might be irregular but slow most of the time. Mucus moves at $2-5 \mathrm{~mm} / \mathrm{min}$ $(40,41)$, which corresponds to an estimated shear stress compatible with the adhesive properties of N. meningitidis. In the nasopharynx, flow can occasionally reach high values upon sneezing, swallowing, et cetera, but the present results show that $N$. meningitidis is well adapted to such variations; once the bacterium is bound, it does not detach. Furthermore, the presence of flow does not prevent bacteria from proliferating at the cell surface. Accordingly, the results de- scribed here on endothelial cells also apply to epithelial cells (unpublished data). The mechanical properties of N. meningitidis adhesion are therefore adapted to life in the nasopharynx and these properties then influence the clinical outcome of the infection.

The absence of specialization for adhesion under high flow first appeared as contradictory with the average blood velocities reported in the brain, but one has to take into account the tremendous heterogeneity of cerebral microcirculation reported by others $(30,31)$. The results using a rat model show that at the capillary level, cerebral microcirculation occasionally reaches sufficiently low velocities to allow adhesion. Direct observation of red blood cells circulating in rat brain capillaries shows that they occasionally slow down or even stop for various lengths of time before moving along the capillary. Human cerebral microcirculation is generally thought to exhibit lower flow than that of rat, suggesting that in humans, conditions allowing neisserial adhesion might occur more frequently. The mechanism underlying the temporary slowing down of flow through certain capillaries is unknown, although it is likely to be tightly regulated. Astrocytes partially surround the endothelial cells via long cytoplasmic processes and could be involved in this process. They are involved in flow control as these cells have been shown to influence the diameter of small arterioles $(42,43)$. Consistently, the slowing down of blood flow is only short lived and erythrocyte velocities rapidly return to average values. Our results also show that once adhesion has occurred, it is very resistant to detachment. Furthermore, once capillary blood flow has accelerated back to its normal level, meningococci not only remain attached but they proliferate to form compact colonies. This observation raised the issue of whether growth in the presence of flow could alter bacterial physiology in such a way as to allow adhesion at high flow levels. This effect would allow dividing bacteria to adhere at high flow leading to the formation of colonies. To test this idea, we harvested bacteria growing on the surface of cells in the presence of flow and used them to reinfect endothelial cells; however, increasing the flow level led to a sharp inhibition of attachment for bacteria grown in suspension (unpublished data). It should be pointed out that Tfp mediate adhesion to host cells not only by providing cell-binding properties but also by mediating bacteria-bacteria interaction, thus allowing bacterial aggregation. As a consequence, during growth on the cell surface, a dividing bacterium remains attached to neighboring bacteria and is therefore never free in suspension. These experiments strongly suggest that bacteria-bacteria interactions are strong enough to resist the effect of the flow. A possible scenario for the early stages of invasive meningococcemia would be the following: bacteria access the bloodstream, eventually flow through a brain capillary exhibiting low flow (corresponding to a shear stress level $<0.5$ dynes $/ \mathrm{cm}^{2}$ ), adhesion occurs, the flow accelerates back to average levels but bacteria remain attached, and proliferate in aggregates, thus favoring crossing of the BBB. 
Our description of the fulminant meningococcal sepsis case is in agreement with the aforementioned sequence of events. Immunohistological analysis of this case did not show bacteria in the circulation or inside blood cells but associated with the vessel walls in various organs. Furthermore, this study showed that the attachment pattern of bacteria is not random. Strikingly, bacteria are found associated mainly with capillaries but not with arterioles or venules. In the brain, approximately fourfold more bacterial colonies can be found in white matter than in gray matter, despite the larger number of capillaries present in gray matter. In light of these properties of the brain microcirculation, the adhesion pattern could be explained by local and temporary flow velocity reductions in capillaries as visualized in physiological conditions. It is possible that in certain regions of the brain such as the white matter, the occurrence of low perfusion in capillaries is more frequent. Given the large bacterial aggregates occasionally observed in the meningococcemia patient, an alternative model would be that preformed bacterial aggregates become trapped in capillaries; however, this hypothesis is contradicted by the fact that aggregates are never observed in Gram stains of blood or cerebrospinal fluid samples from patients with meningococcemia.

One increasingly recognized characteristic of septic shock is the alteration of microvascular blood flow (44). An alternative but not exclusive scenario to the aforementioned one presented to explain the attachment pattern is, therefore, microvessel dysfunction in sepsis cases. Experimental evidence as well as clinical studies point to a specific defect in small vessel $(<20 \mu \mathrm{m})$ perfusion in patients with sepsis. In the same conditions, larger vessels $(>20 \mu \mathrm{m})$ are normally perfused (45). Meningococcal endotoxin is thought to trigger the host response that leads to capillary leakage, inappropriate vascular tone, and intravascular microthrombi leading to microcirculation dysfunction (46). An alternative sequence of events could therefore be the following: bacteria proliferate in the blood and trigger inflammation and sepsis; microvasculature becomes dysfunctional and some capillaries underperfused or even stagnant, thus allowing adhesion to the vessel walls and crossing of the BBB. For the sepsis case we described here, it is difficult to discriminate between adhesion as the result of "physiological" slow flow from adhesion as a result of sepsis-induced capillary underperfusion as both might have occurred successively. It is likely, that in the early phases of infection, adhesion is mainly a result of the properties of brain capillaries to transiently reduce their flow. Subsequent blood flow alterations during sepsis could be responsible for an amplification of the adhesion process and for the numerous colonization sites observed in the sepsis case described here.

Collectively, results presented in this study demonstrate that shear stress values are a key determinant in defining where N. meningitidis will bind in the vasculature. We showed that in rat brain, certain but not all capillaries would allow $N$. meningitidis binding and subsequent growth. It is likely that large colonies formed in the lumen of cerebral vessels will favor crossing of the $\mathrm{BBB}$ and access to the brain where the bacteria will find a unique niche practically free of the immune system. The mechanism for crossing the BBB still remains undetermined. In vitro experiments favor a transcellular pathway because, in these conditions, N. meningitidis infection does not affect tight junctions formed by the cells $(47,48)$. Interestingly, however, local ischemia is known to lead to a temporary breach in the BBB (49). The presence of large bacterial aggregates clogging small cerebral vessels as described in Fig. 1 could therefore alter the integrity of the BBB in such a way that it would allow access of bacteria to the brain.

\section{MATERIALS AND METHODS}

Histology and immunohistochemistry. During the autopsy of a 2-mo-old infant (10), the brain as well as other organs were removed and embedded in paraffin. Samples from different organs were prepared for routine histology. For immunohistochemistry, paraffin was first removed and slides were incubated in $50 \mathrm{mM}$ Tris containing 1\% BSA for $10 \mathrm{~min}$. The three subsequent incubation steps were done in the same buffer for periods of $20 \mathrm{~min}$. Samples were incubated in rabbit polyclonal antiserum raised against the $N$. meningitidis ROU strain (50) isolated from the same patient and diluted 1:2,000. After rinsing in $50 \mathrm{mM}$ Tris, samples were incubated with biotinylated secondary antibody directed against mouse and rabbit IgG (DakoCytomation) diluted according to the manufacturer's instructions (DakoCytomation). After washing, samples were incubated in horseradish peroxidase-conjugated streptavidin also diluted according to manufacturer's instructions. Finally peroxidase activity was revealed using $3,3^{\prime}$ diaminobenzidine (DAB).

Bacterial strains and growth conditions. N. meningitidis 8013 clone 12 is a serogroup C clinical isolate, expressing a class I SB pilin, Opa-, Opc-, $\mathrm{PilC}^{+} / \mathrm{PilC}^{+}$as described previously (23). N. meningitidis was grown on GCB agar plates (Difco) containing Kellogg's supplements and when required, $100 \mu \mathrm{g} / \mathrm{ml}^{-1}$ kanamycin, $5 \mu \mathrm{g} / \mathrm{ml}^{-1}$ or chloramphenicol at $37^{\circ} \mathrm{C}$ in moist atmosphere containing $5 \% \mathrm{CO}_{2}$. E. coli transformants were grown on liquid or solid Luria-Bertani medium (Difco) containing $20 \mu \mathrm{g} / \mathrm{ml}^{-1}$ chloramphenicol or $30 \mu \mathrm{g} / \mathrm{ml}^{-1}$ colistin when necessary. Mutations in the pilE, pilC1, and pilT genes were introduced into the N. meningitidis chromosome by natural transformation of chromosomal DNA extracted from a library of transposition mutants described elsewhere (6). Strains expressing the SA, SB, and $\mathrm{SB}^{*}$ pilins as transcriptional fusions to the kanamycin resistance cassette have been described elsewhere (23). N. meningitidis was made to express the GFP by introducing the pAM239 plasmid (51) by conjugation. The competent E. coli HB101 strain containing plasmid pRK24 (52) was first transformed with the pAM239 plasmid. Before conjugation, the HB101 E. coli strain containing plasmids pAM239 and pRK24 and N. meningitidis were grown to exponential phase for $2 \mathrm{~h}$ at $37^{\circ} \mathrm{C}$ in LB and RPMI 1640 serum (PAA Laboratories $\mathrm{GmbH}$ ), respectively. A sample of Neisseria culture $(100 \mu \mathrm{l})$ was mixed with a sample of $E$. coli culture $(10 \mu \mathrm{l})$ on a sterile $0.45-\mu \mathrm{m}$ filter (Millipore), placed on a GCB plate, and incubated for $15 \mathrm{~h}$ at $37^{\circ} \mathrm{C}$. The filter was rinsed with $3 \mathrm{ml}$ of liquid $\mathrm{GCB}$ and the resulting bacterial suspension was plated on a GCB agar plate containing chloramphenicol $\left(5 \mu \mathrm{g} / \mathrm{ml}^{-1}\right)$ and colistin $\left(30 \mu \mathrm{g} / \mathrm{ml}^{-1}\right)$.

Cell culture. Primary HUVECs (PromoCell) were used between passages 1 and 10 and grown at $37^{\circ} \mathrm{C}$ in a humidified incubator under $5 \% \mathrm{CO}_{2}$ in Endo-SFM (Invitrogen) supplemented with 10\% heat-inactivated FBS (Invitrogen), $5 \mathrm{UI} / \mathrm{ml}$ of heparin (Sigma-Aldrich) and $40 \mu \mathrm{g} / \mathrm{ml}$ of endothelial cell growth supplement (Harbor Bioproducts). The hCMEC/D3 human brain endothelial cell line was cultured in EGM-2 medium (Biowhittaker/ Cambrex) and supplemented as indicated by the manufacturer (27). The RBE4 immortalized rat brain endothelial cell line was cultured in a 
50/50 mixture of MEM $\alpha$ medium and NUT.MIX.F-10 (HAM) medium (Invitrogen) supplemented with $10 \% \mathrm{FBS}, 1 \mathrm{ng} / \mathrm{ml} \beta$-FGF (Invitrogen), $10 \mathrm{mM}$ Hepes, pH 7.3, and $300 \mu \mathrm{g} / \mathrm{ml} \mathrm{G418} \mathrm{(24).} \mathrm{For} \mathrm{flow} \mathrm{chamber} \mathrm{assays,}$ cells were plated on 8 -mm-diameter wells on glass slides otherwise coated with hydrophobic teflon. Before seeding at a density of $10^{4}$ cells per well, slides were coated with fibronectin $(10 \mu \mathrm{g} / \mathrm{ml}$ for $1 \mathrm{~h})$.

Laminar flow chamber experiments. Before the assay, bacteria grown on GCB agar plates were adjusted to $\mathrm{OD}_{600}=0.02$ in prewarmed RPMI 1640 medium containing $10 \%$ FBS and incubated for $1 \mathrm{~h} 30 \mathrm{~min}$ at $37^{\circ} \mathrm{C}$. GFP expression was induced by adding $1 \mathrm{mM}$ IPTG in the culture medium for an additional $1 \mathrm{~h} 30 \mathrm{~min}$. Cells grown on glass slides were placed in a parallel plate flow chamber $(3.3 \mathrm{~cm} \times 0.6 \mathrm{~cm} \times 250 \mu \mathrm{m}$; Immunetics $)$ and sealed with a vacuum. Experiments using the flow chamber were performed in Endo-SFM supplemented with $2 \%$ serum and maintained at $37^{\circ} \mathrm{C}$ with a heated platform (Minitub). The bacterial culture was diluted to $7.5 \times 10^{7}$ bacteria $/ \mathrm{ml}$ (unless stated otherwise) and was introduced into the chamber using a syringe pump (Vial Medical, Becton Dickinson, or Harvard Apparatus) at various flow rates to produce various wall shear stress levels. Adhesion of bacteria was recorded using an Olympus CKX41 inverted microscope with a $20 \mathrm{x}$ objective, equipped with a shutter for the fluorescence lamp and a Hamamatsu ORCA285 CCD camera. The Openlab darkroom software (Improvision) controlled the shutter and camera for video timelapse microscopy. Videos were recorded at one frame every $5 \mathrm{~s}$. The field under observation corresponded to $425 \mu \mathrm{m}$ by $320 \mu \mathrm{m}$ with a resolution of $0.63 \mu \mathrm{m}$ per pixel.

Quantitative image analysis (QUIA). A dedicated semiautomatic program was developed to detect, count, and track N. meningitidis or red blood cells from fluorescence image sequences. Spot detection was performed automatically by a multiresolution algorithm based on wavelet decomposition of the image and wavelet coefficient thresholding and correlation that outputted binary masks for each detected object (53). Resulting binary masks were then used to compute geometrical parameters such as centroid, surface, principal axes, and roundness with a central moment algorithm on the basis of which the algorithm is able to discern bacteria or erythrocytes from background fluorescent structures. The program yielded data tables for each time point that were used for generating values in the figures (54). We defined bacteria as adherent if they remained stationary at least five images. Depending on the experiment, the number of bacteria was either determined as a function of time on 1 field or 10 fields ( $\sim 300$ cells) were averaged after a given incubation time to gain statistical significance.

In vivo imaging of rat brain microcirculation. In vivo investigations of rat cerebral microcirculation through a cranial window were performed as described previously (55). The area under the window corresponded to a distal territory of the middle cerebral artery. All physiological parameters monitored on the animals during the study were within the normal range. The local microcirculation of five rats was continuously monitored through the closed cranial window using a Viewscan DVC-250 confocal laser-scanning unit (BioRad Laboratories) attached to an Optiphot-2 fluorescence microscope (Nikon). The light source was an argon/krypton laser. The objective was a Nikon water immersion lens (x20). A tracer dose of FITC-dextran (Sigma-Aldrich) injected via the femoral vein was used to clearly visualize microvessels. Erythrocytes from the blood of a different animal were labeled with fluorescein-isothiocyanate and injected into the femoral vein. Polybead latex microsphere $(1 \mu \mathrm{m})$ was purchased from Polyscience. Images from one single plane were recorded at video speed $(25$ frames/s) with a SIT camera (C-2400, Hamamatsu Photonics). Resulting images from videotapes were digitized and analyzed with the Quia program. The studies reported here conform to the principles outlined by the National Institutes of Health guidelines for the care and use of animals in biomedical research. Experiments were approved by the French ministry of agriculture and the regional ethics committee for animal experimentation (Ile de France, Paris).
Calculation of shear stress. For the flow chamber experiments, shear stress was determined using the standard formula $T_{w}=6 \eta \mathrm{Q} / \mathrm{wh}^{2}$ where $\mathrm{Q}$ is the flow rate, and $\mathrm{w}$ and $\mathrm{h}$ are the chamber width and height, respectively. For the intravital experiments in rats, shear stress was calculated from the measurement of microvascular flow velocities, blood viscosity and the radius of the microvessel from the formula $T_{w}=4 V \eta / r$, where $T_{w}$ is wall shear stress, $\mathrm{V}$ is microvascular flow velocity, $\eta$ is blood viscosity, and $r$ is the radius of the blood vessel. Viscosity was estimated for a hematocrit of 0.23 as reported by Pries et al. (56) for $8-\mu \mathrm{m}$ capillaries from the in vivo viscosity law described by the same group (57). The difference between blood velocity and erythrocyte velocity generated by the Fahraeus-Lindquist effect was not taken into account and blood velocity in capillaries was approximated by the velocity of red blood cells.

Online supplemental material. Video 1 shows the adhesion of fluorescent bacteria introduced over endothelial cells in the presence of low-level shear stress $\left(0.04\right.$ dynes $\left./ \mathrm{cm}^{2}\right)$. The video is accelerated 50 times; real-time duration is $10 \mathrm{~min}$. Video 2 shows rat brain microcirculation visualized by fluorescently labeled erythrocytes through a cranial window with laser scanning microscopy. The videos showing erythrocytes movement such as Videos 2 and 3 are not accelerated. Video 3 illustrates the tracking of erythrocytes using the Quia image treatment software to determine blood velocity in a capillary. Video 4 shows an example of a temporary blood flow reduction in a rat brain capillary. Video 5 illustrates the proliferation of $N$. meningitidis on the surface of endothelial cells in the presence of shear stress $\left(2\right.$ dynes $\left./ \mathrm{cm}^{2}\right)$ over a period of $7 \mathrm{~h}$ and $30 \mathrm{~min}$. Online supplemental material is available at http://www.jem.org/cgi/content/full/jem.20060482/DC1.

The authors would like to thank V. Pelicic for providing numerous transposon insertion mutants, discussions, and for reviewing the manuscript. The authors also express their gratitude to P.O. Couraud for providing the RBE4 and hCMEC/D3 cell lines. The authors wish to thank R. Isberg for pointing out the importance of shear forces in bacterial adhesion. The authors thank P. Martin and A. Maria LennonDumenil for reviewing the manuscript. The authors are also grateful to P. Bongrand for helpful discussions concerning the biophysical aspects of study.

The work was funded by INSERM, CNRS, and Université René Descartes.

E. Mairey was funded by the French Ministry of research and higher education.

A. Genovesio was founded by the ANRS (Agence Nationale de Recherches sur le

SIDA) and the Pasteur Institute.

The authors have no conflicting financial interests.

Submitted: 1 March 2006

Accepted: 19 June 2006

\section{REFERENCES}

1. van Deuren, M., P. Brandtzaeg, and J.W. van der Meer. 2000. Update on meningococcal disease with emphasis on pathogenesis and clinical management. Clin. Microbiol. Rev. 13:144-166.

2. Caugant, D.A., E.A. Hoiby, P. Magnus, O. Scheel, T. Hoel, G. Bjune, E. Wedege, J. Eng, and L.O. Froholm. 1994. Asymptomatic carriage of Neisseria meningitidis in a randomly sampled population. J. Clin. Microbiol. 32:323-330.

3. Gold, R., I. Goldschneider, M.L. Lepow, T.F. Draper, and M. Randolph. 1978. Carriage of Neisseria meningitidis and Neisseria lactamica in infants and children. J. Infect. Dis. 137:112-121.

4. Sim, R.J., M.M. Harrison, E.R. Moxon, and C.M. Tang. 2000. Underestimation of meningococci in tonsillar tissue by nasopharyngeal swabbing. Lancet. 356:1653-1654.

5. Mackinnon, F.G., R. Borrow, A.R. Gorringe, A.J. Fox, D.M. Jones, and A. Robinson. 1993. Demonstration of lipooligosaccharide immunotype and capsule as virulence factors for Neisseria meningitidis using an infant mouse intranasal infection model. Microb. Pathog. 15: 359-366.

6. Geoffroy, M.C., S. Floquet, A. Metais, X. Nassif, and V. Pelicic. 2003. Large-scale analysis of the meningococcus genome by gene disruption: resistance to complement-mediated lysis. Genome Res. 13:391-398. 
7. Cahalane, S.F., and M. Waters. 1975. Fulminant meningococcal septicaemia. A hospital experience. Lancet. 2:120-121.

8. Nassif, X. 1999. Interaction mechanisms of encapsulated meningococci with eucaryotic cells: what does this tell us about the crossing of the blood-brain barrier by Neisseria meningitidis? Curr. Opin. Microbiol. 2:71-77.

9. Simberkoff, M.S., N.H. Moldover, and J. Rahal Jr. 1980. Absence of detectable bactericidal and opsonic activities in normal and infected human cerebrospinal fluids. A regional host defense deficiency. J. Lab. Clin. Med. 95:362-372.

10. Pron, B., M.K. Taha, C. Rambaud, J.C. Fournet, N. Pattey, J.P. Monnet, M. Musilek, J.L. Beretti, and X. Nassif. 1997. Interaction of Neisseria maningitidis with the components of the blood-brain barrier correlates with an increased expression of PilC. J. Infect. Dis. 176:1285-1292.

11. DeVoe, I.W., and J.E. Gilchrist. 1975. Pili on meningococci from primary cultures of nasopharyngeal carriers and cerebrospinal fluid of patients with acute disease. J. Exp. Med. 141:297-305.

12. Swanson, J. 1973. Studies on gonococcus infection. IV. Pili: their role in attachment of gonococci to tissue culture cells. J. Exp. Med. 137:571-589.

13. Virji, M., H. Kayhty, D.J. Ferguson, C. Alexandrescu, J.E. Heckels, and E.R. Moxon. 1991. The role of pili in the interactions of pathogenic Neisseria with cultured human endothelial cells. Mol. Microbiol. 5:1831-1841.

14. Cohen, M.S., and J.G. Cannon. 1999. Human experimentation with Neisseria gonorrhoeae: progress and goals. J. Infect. Dis. 179: S375-S379.

15. Carbonnelle, E., S. Helaine, L. Prouvensier, X. Nassif, and V. Pelicic. 2005. Type IV pilus biogenesis in Neisseria meningitidis: PilW is involved in a step occurring after pilus assembly, essential for fibre stability and function. Mol. Microbiol. 55:54-64.

16. Strom, M.S., and S. Lory. 1993. Structure-function and biogenesis of the type IV pili. Annu. Rev. Microbiol. 47:565-596.

17. Bradley, C.J., N.J. Griffiths, H.A. Rowe, R.S. Heyderman, and M. Virji. 2005. Critical determinants of the interactions of capsuleexpressing Neisseria meningitidis with host cells: the role of receptor density in increased cellular targeting via the outer membrane Opa proteins. Cell. Microbiol. 7:1490-1503.

18. Johansson, L., A. Rytkonen, P. Bergman, B. Albiger, H. Kallstrom, T. Hokfelt, B. Agerberth, R. Cattaneo, and A.B. Jonsson. 2003. CD46 in meningococcal disease. Science. 301:373-375.

19. Wilson, T.D., J.K. Shoemaker, R. Kozak, T.Y. Lee, and A.W. Gelb. 2005. Reflex-mediated reduction in human cerebral blood volume. J. Cereb. Blood Flow Metab. 25:136-143.

20. Helenius, J., J. Perkio, L. Soinne, L. Ostergaard, R.A. Carano, O. Salonen, S. Savolainen, M. Kaste, H.J. Aronen, and T. Tatlisumak. 2003. Cerebral hemodynamics in a healthy population measured by dynamic susceptibility contrast MR imaging. Acta Radiol. 44: 538-546.

21. Pierres, A., A.M. Benoliel, C. Zhu, and P. Bongrand. 2001. Diffusion of microspheres in shear flow near a wall: use to measure binding rates between attached molecules. Biophys. J. 81:25-42.

22. Loscalzo, J., and A. Schafer, editors. 2002. Thrombosis and Hemorrhage. Lippincott Williams and Wilkins, Philadelphia. $1170 \mathrm{pp}$.

23. Nassif, X., J. Lowy, P. Stenberg, P. O'Gaora, A. Ganji, and M. So. 1993. Antigenic variation of pilin regulates adhesion of Neisseria meningitidis to human epithelial cells. Mol. Microbiol. 8:719-725.

24. Roux, F., O. Durieu-Trautmann, N. Chaverot, M. Claire, P. Mailly, J.M. Bourre, A.D. Strosberg, and P.O. Couraud. 1994. Regulation of gamma-glutamyl transpeptidase and alkaline phosphatase activities in immortalized rat brain microvessel endothelial cells. J. Cell. Physiol. 159:101-113.

25. Merz, A.J., M. So, and M.P. Sheetz. 2000. Pilus retraction powers bacterial twitching motility. Nature. 407:98-102.

26. Pujol, C., E. Eugene, M. Marceau, and X. Nassif. 1999. The meningococcal PilT protein is required for induction of intimate attachment to epithelial cells following pilus-mediated adhesion. Proc. Natl. Acad. Sci. USA. 96:4017-4022.
27. Weksler, B.B., E.A. Subileau, N. Perriere, P. Charneau, K. Holloway, M. Leveque, H. Tricoire-Leignel, A. Nicotra, S. Bourdoulous, P. Turowski, et al. 2005. Blood-brain barrier-specific properties of a human adult brain endothelial cell line. FASEB J. 19:1872-1874.

28. Lipowsky, H.H., S. Kovalcheck, and B.W. Zweifach. 1978. The distribution of blood rheological parameters in the microvasculature of cat mesentery. Circ. Res. 43:738-749.

29. Stepp, D.W., Y. Nishikawa, and W.M. Chilian. 1999. Regulation of shear stress in the canine coronary microcirculation. Circulation. 100:1555-1561.

30. Hudetz, A.G., G. Feher, D.E. Knuese, and J.P. Kampine. 1994 Erythrocyte flow heterogeneity in the cerebrocortical capillary network. Adv. Exp. Med. Biol. 345:633-642.

31. Villringer, A., A. Them, U. Lindauer, K. Einhaupl, and U. Dirnagl. 1994. Capillary perfusion of the rat brain cortex. An in vivo confocal microscopy study. Circ. Res. 75:55-62.

32. Kirchner, M., D. Heuer, and T.F. Meyer. 2005. CD46-independent binding of neisserial type IV pili and the major pilus adhesin, PilC, to human epithelial cells. Infect. Immun. 73:3072-3082.

33. Tobiason, D.M., and H.S. Seifert. 2001. Inverse relationship between pilus-mediated gonococcal adherence and surface expression of the pilus receptor, CD46. Microbiology. 147:2333-2340.

34. McEver, R.P. 2002. Selectins: lectins that initiate cell adhesion under flow. Curr. Opin. Cell Biol. 14:581-586.

35. Thomas, W.E., E. Trintchina, M. Forero, V. Vogel, and E.V. Sokurenko. 2002. Bacterial adhesion to target cells enhanced by shear force. Cell. 109:913-923.

36. Thomas, W.E., L.M. Nilsson, M. Forero, E.V. Sokurenko, and V. Vogel. 2004. Shear-dependent 'stick-and-roll' adhesion of type 1 fimbriated Escherichia coli. Mol. Microbiol. 53:1545-1557.

37. Isberg, R.R., and P. Barnes. 2002. Dancing with the host; flowdependent bacterial adhesion. Cell. 110:1-4.

38. Criss, A.K., K.A. Kline, and H.S. Seifert. 2005. The frequency and rate of pilin antigenic variation in Neisseria gonorrhoeae. Mol. Microbiol. 58:510-519.

39. Taha, M.K., A.E. Deghmane, A. Antignac, M.L. Zarantonelli, M. Larribe, and J.M. Alonso. 2002. The duality of virulence and transmissibility in Neisseria meningitidis. Trends Microbiol. 10:376-382.

40. Salathe, M. T.G. O'riordan, and A. Wanner. 1997. Mucociliary clearance. In The Lung: Scientific Foundations. R.G. Crystal, J.B. West, P.J. Barnes, and E.R. Weibel, editors. Lippincott-Raven, Philadelphia. $2462 \mathrm{pp}$.

41. Knowles, M.R., and R.C. Boucher. 2002. Mucus clearance as a primary innate defense mechanism for mammalian airways. J. Clin. Invest. 109:571-577.

42. Mulligan, S.J., and B.A. MacVicar. 2004. Calcium transients in astrocyte endfeet cause cerebrovascular constrictions. Nature. 431:195-199.

43. Koehler, R.C., D. Gebremedhin, and D.R. Harder. 2006. Role of astrocytes in cerebrovascular regulation. J. Appl. Physiol. 100: 307-317.

44. Vincent, J.L., and D. De Backer. 2005. Microvascular dysfunction as a cause of organ dysfunction in severe sepsis. Crit. Care. 9:S9-S12.

45. De Backer, D., J. Creteur, J.C. Preiser, M.J. Dubois, and J.L. Vincent. 2002. Microvascular blood flow is altered in patients with sepsis. Am. J. Respir. Crit. Care Med. 166:98-104.

46. Caputo, G.L., G. Baldwin, G. Alpert, J. Parsonnet, Z.A. Gillis, G. Siber, and G. Fleisher. 1992. Effect of meningococcal endotoxin in a rabbit model of shock. Circ. Shock. 36:104-112.

47. Merz, A.J., D.B. Rifenbery, C.G. Arvidson, and M. So. 1996. Traversal of a polarized epithelium by pathogenic Neisseriae: facilitation by type IV pili and maintenance of epithelial barrier function. Mol. Med. 2:745-754.

48. Pujol, C., E. Eugene, L. de Saint Martin, and X. Nassif. 1997. Interaction of Neisseria meningitidis with a polarized monolayer of epithelial cells. Infect. Immun. 65:4836-4842.

49. Pinard, E., N. Engrand, and J. Seylaz. 2000. Dynamic cerebral microcirculatory changes in transient forebrain ischemia in rats: involvement of type I nitric oxide synthase. J. Cereb. Blood Flow Metab. 20: 1648-1658. 
50. Eugene, E., I. Hoffmann, C. Pujol, P.O. Couraud, S. Bourdoulous, and X. Nassif. 2002. Microvilli-like structures are associated with the internalization of virulent capsulated Neisseria meningitidis into vascular endothelial cells. J. Cell Sci. 115:1231-1241.

51. Solomon, J.M., A. Rupper, J.A. Cardelli, and R.R. Isberg. 2000. Intracellular growth of Legionella pneumophila in Dictyostelium discoideum, a system for genetic analysis of host-pathogen interactions. Infect. Immun. 68:2939-2947.

52. Poyart, C., and P. Trieu-Cuot. 1997. A broad-host-range mobilizable shuttle vector for the construction of transcriptional fusions to $\beta$-galactosidase in gram-positive bacteria. FEMS Microbiol. Lett. 156:193-198.

53. Olivo-Marin, J.-C. 2002. Extraction of spots in biological images using multiscale products. Pattern Recognit. 35:1989-1996.
54. Genovesio, A., and J.-C. Olivo-Marin. 2003. Tracking fluorescent spots in biological video. Proceedings of SPIE. 4964:98-105.

55. Seylaz, J., R. Charbonne, K. Nanri, D. Von Euw, J. Borredon, K. Kacem, P. Meric, and E. Pinard. 1999. Dynamic in vivo measurement of erythrocyte velocity and flow in capillaries and of microvessel diameter in the rat brain by confocal laser microscopy. J. Cereb. Blood Flow Metab. 19:863-870.

56. Pries, A.R., A. Fritzsche, K. Ley, and P. Gaehtgens. 1992. Redistribution of red blood cell flow in microcirculatory networks by hemodilution. Circ. Res. 70:1113-1121.

57. Pries, A.R., T.W. Secomb, T. Gessner, M.B. Sperandio, J.F. Gross, and P. Gaehtgens. 1994. Resistance to blood flow in microvessels in vivo. Circ. Res. 75:904-915. 